\title{
CONCRETO AUTOCICATRIZANTE PELA INTRODUÇÃO DE BACTÉRIAS - UMA REVISÃO
}

\author{
L. R. S. CARNEIRO ${ }^{1 *}$, J. PAULA $^{1}$, J. E. AGUIAR ${ }^{2}$, P. LUDVIG $^{1}$ \\ ${ }^{1}$ Programa de Pós-Graduação em Engenharia Civil, Centro Federal de Educação Tecnológica de Minas Gerais, Belo \\ Horizonte, Brasil. \\ 2Instituto de Educação Continuada, Pontifícia Universidade Católica de Minas Gerais, Belo Horizonte, Brasil.
}

\begin{abstract}
RESUMO
Este trabalho explora as características, limitações e desafios de concretos autocicatrizantes pela introdução de bactérias. Uma revisão sistemática foi realizada, sobretudo, por meio da seleção de publicações dos últimos dez anos na área. Em condições favoráveis, as bactérias induzem a precipitação de carbonato de cálcio, o qual é depositado nos poros do concreto, diminuindo sua porosidade e aumentando sua resistência mecânica. O tipo de bactéria utilizado e seus nutrientes afetam diretamente os produtos formados. Bactérias ureolíticas do gênero Bacillus são o tipo mais investigado. O efeito de autocicatrização é mais pronunciado nas primeiras idades do concreto, diminuindo progressivamente ao longo do tempo. O encapsulamento ou imobilização das bactérias pode prolongar sua vida útil no meio alcalino do concreto.
\end{abstract}

Palavras-chave: concreto autocicatrizante; precipitação de calcita induzida microbiologicamente; bactérias no concreto.

\begin{abstract}
This paper explores the caracteristics, limitations and challenges of bacteria based self-healing concrete. A systematic review was carried out by selecting publications of the last ten years on the area. Under proper conditions, bacteria induce the precipitation of calcium carbonate, which is deposited inside the concrete pores, decreasing its porosity and increasing its compressive strength. Bacteria type and its nutrientes, directly affect the precipitated products. Ureolytic bacteria, of the genus Bacillus, are the most investigated type, due to their high resistance to alcaline media. Self-healing effect is higher at early ages concretes, dropping progressively over time. In order to avoid this, bacteria are encapsulated or immobilized by protective materials, which increases theirs life cycle inside concrete's alcaline medium.
\end{abstract}

Keywords: self-healing concrete; microbially induced calcite precipitation; bacteria in concrete;

\section{RESUMEN}

Este artículo explora las características, limitaciones y desafíos de los hormigones autocurativos mediante la introducción de bacterias. Se realizó una revisión sistemática principalmente seleccionando publicaciones de los últimos diez años en el área. En condiciones favorables, las bacterias inducen la precipitación de carbonato de calcio, que se deposita en los poros del hormigón, reduciendo su porosidad y aumentando su resistencia mecánica. El tipo de bacteria utilizada y sus nutrientes afectan directamente los productos formados. Las bacterias ureolíticas del género Bacillus son el tipo más investigado. El efecto de autocuración es más pronunciado en las primeras edades del hormigón, disminuyendo progresivamente con el tiempo. La encapsulación o inmovilización de bacterias puede prolongar su vida útil en el medio alcalino del hormigón.

Palabras clave: hormigón autocurativo; precipitación de calcita microbiológicamente inducida; bacterias en el concreto. 


\section{INTRODUÇÃO}

O concreto é um material compósito com baixa resistência à tração. Quando sujeito a esforços de retração, à expansões volumétricas devido à variação de temperatura, dentre outros, o concreto geralmente fissura. A própria norma brasileira ABNT 6118:2014, Projeto de estruturas de concreto Procedimentos, prevê fissuras de até $0,2 \mathrm{~mm}$ de largura para edificações expostas a ambientes com classe de agressividade IV. Fissuras de até $0,2 \mathrm{~mm}$ são fechadas pelo próprio concreto, o qual continua a hidratar com o passar do tempo. Porém, aberturas maiores permitem o ingresso de substâncias deletérias presentes no meio ambiente, as quais podem atacar as armaduras e o concreto, comprometendo a durabilidade da edificação e elevando os gastos com manutenção (Jonkers et al., 2010).

A ideia de um concreto com propriedades autocicatrizantes surgiu na década de 1990. A propriedade de autocicatrização pode ser obtida por meio da introdução de catalizadores cristalinos, fibras, esporos de bactérias e seus nutrientes, dentre outros, na matriz cimentícia. A aplicação de bactérias em compósitos cimentícios tem como princípio o fenômeno da precipitação de calcita microbiologicamente induzida (MICP - Microbially Induced Calcite Precipitation). Tal fenômeno ocorre por meio de diversos mecanismos, dentre os quais se destaca a degradação (hidrólise) da ureia pelas chamadas bactérias ureolíticas (Mondal e Ghosh, 2019). Tais microorganismos produzem uma enzima denominada urease, a qual promove a hidrólise da ureia, liberando íons carbonato $\left(\mathrm{CO}_{3}{ }^{2-}\right)$. Estes, por sua vez, se ligam a íons cálcio $\left(\mathrm{Ca}^{2+}\right)$, presentes no ambiente ou fornecidos por uma fonte específica, formando carbonato de cálcio $\left(\mathrm{CaCO}_{3}\right)$, sobretudo na forma de cristais de calcita. Estes cristais são depositados nas fissuras e poros do concreto, cicatrizando-o, densificando-o e melhorando suas propriedades mecânicas (Jonkers et al., 2010; Achal et al., 2011; Siddique et al., 2016).

O desenvolvimento de concretos autocicatrizantes pela introdução de bactérias tem como principal objetivo a redução de custos com manutenção e o aumento da vida útil das edificações. No entanto, por se tratar de um técnica relativamente nova e, portanto, em desenvolvimento, algumas questões, referentes à sua eficiência, necessitam de maior compreensão. Dentre elas, cita-se: a capacidade autocicatrizante do material a curto e longo prazo, a relação entre a capacidade cicatrizante e o método de aplicação das bactérias no concreto, e os efeitos da adição de bactérias nas propriedades de compósitos cimentícios. Este artigo discute estes três aspectos, além de apresentar os princípios da precipitação de calcita induzida microbiologicamente (MICP), destacando-se o papel das bactérias ureolíticas e a influência que o tipo e a concentração destas bactérias e seus nutrientes exercem sobre os produtos formados. Os dados apresentados neste trabalho provém de uma revisão sistemática da literatura, realizada, sobretudo, por meio da seleção de publicações dos últimos 10 anos na área.

\section{PRINCÍPIOS DA MICP E SEUS PRODUTOS}

As bactérias são largamente utilizadas na biotecnologia, devido ao seu tamanho reduzido $(0,5-10 \mu \mathrm{m})$, grande diversidade fisiológica e capacidade de reprodução assexuada em curto período tempo, através de fissão binária (Borges, 2015). Grande parte das bactérias é capaz de precipitar carbonato de cálcio, por meio de diversos mecanismos. Dentre eles, pode-se citar a fotossíntese oxigênica, a fotossíntese anoxigênica, a oxidação do metano e os ciclos do enxofre e do nitrogênio (Mondal et al. 2019). Boa parte das pesquisas envolvendo compósitos cimentícios auto-cicatrizantes utiliza bactérias que participam do ciclo do nitrogênio e, de maneira particular, da degradação de ureia ou ácido úrico. São as chamadas bactérias ureolíticas. O presente tópico aborda este mecanismo de MICP, explicando suas etapas e discutindo os produtos formados.

\subsection{MICP por meio de degradação de ureia}

Ao se tratar de materiais cimentícios, é importante considerar um ambiente extremamente alcalino, com 
poros de pequeno tamanho e pouco favorável à reprodução e sobrevivência de microoganismos. Por este motivo, no que concerne a fabricação de compósitos auto-cicatrizantes pela introdução de bactérias, pesquisadores costumam utilizar as chamadas bactérias ureolíticas, capazes de degradar ureia. Tais microorganismos produzem uma enzima, denominada urease, que catalisa o processo de hidrólise da ureia, acelerando a precipitação de carbonato de cálcio. As Equações 1 a 6 apresentam as reações químicas do processo de precipitação de carbonato de cálcio por bactérias ureolíticas.

$$
\begin{aligned}
& \mathrm{CO}\left(\mathrm{NH}_{2}\right)_{2}+\mathrm{H}_{2} \mathrm{O} \rightarrow \mathrm{NH}_{2} \mathrm{COOH}+\mathrm{NH}_{3} \\
& \mathrm{NH}_{2} \mathrm{COOH}+\mathrm{H}_{2} \mathrm{O} \rightarrow \mathrm{NH}_{3}+\mathrm{H}_{2} \mathrm{CO}_{3} \\
& \mathrm{H}_{2} \mathrm{CO}_{3} \rightarrow \mathrm{HCO}_{3}^{-}+\mathrm{H}^{+} \\
& 2 \mathrm{NH}_{3}+2 \mathrm{H}_{2} \mathrm{O} \rightarrow 2 \mathrm{NH}^{4+}+2 \mathrm{OH}^{-} \\
& 2 \mathrm{OH}^{-}+\mathrm{H}^{+}+\mathrm{HCO}_{3}^{-} \rightarrow \mathrm{CO}_{3}^{2-}+2 \mathrm{H}_{2} \mathrm{O} \\
& \mathrm{CO}_{3}{ }^{2-}+\mathrm{Ca}^{2+} \rightarrow \mathrm{CaCO}_{3}
\end{aligned}
$$

$\mathrm{Na}$ Equação 1, um mol de ureia $\left(\mathrm{CO}\left(\mathrm{NH}_{2}\right)_{2}\right)$ é hidrolisada, formando um mol de amônia $\left(\mathrm{NH}_{3}\right)$ e um mol de carbamato $\left(\mathrm{NH}_{2} \mathrm{COOH}\right)$. $\mathrm{Na}$ Equação 2, o carbamato é hidrolisado, formando um mol adicional de amônia e ácido carbônico $\left(\mathrm{H}_{2} \mathrm{CO}_{3}\right)$. Tais produtos se equilibram com a água e formam bicarbonato $\left(\mathrm{HCO}^{3-}\right)$, duas mol de amônio $\left(2 \mathrm{NH}^{4+}\right)$ e hidroxila $\left(2 \mathrm{OH}^{-}\right)$(Equações 3 e 4). Na Equação 5, tem-se o aumento de $\mathrm{pH}$ e a presença de íons carbonato $\left(\mathrm{CO}_{3}{ }^{2-}\right)$, os quais reagem com íons cálcio $\left(\mathrm{Ca}^{2+}\right)$, previamente fornecidos, e precipitam na forma de carbonato de cálcio $\left(\mathrm{CaCO}_{3}\right)$ (Equação 6) (Siddique e Chahal, 2011). $\mathrm{O} \mathrm{CaCO}_{3}$ é formado na membrana celular da bactéria, a qual apresenta elevado potencial-zeta negativo. Uma vez que se encontre totalmente preenchida por $\mathrm{CaCO}_{3}$, a célula é incapaz de prosseguir com suas atividades metabólicas, transformando-se em endoesporos e passando a agir como fibras orgânicas inertes ou, simplesmente, morrendo (Ramachandran et al, 2001).

Dentre os gêneros de bactérias ureolíticas investigados, o gênero Bacillus, atualmente também denominado Sporosarcina, se mostra como o mais promissor para aplicação em matrizes cimentícias (Jonkers, 2007). Isto porque tais bactérias formam esporos que lhes permitem sobreviver com pouca quantidade de água e nutrientes por muito tempo. Além disso, resistem de maneira razoável ao ambiente extremamente alcalino do concreto. Tipicamente, a formação de uma fissura num material cimentício permite o ingresso de água em seu interior, fazendo com que a bactéria saia de seu estado de latência e inicie suas atividades metabólicas. No caso das bactérias ureolíticas, a energia adquirida com o consumo de nutrientes leva à produção da enzima urease, a qual catalisa a hidrólise da ureia e culmina na precipitação de carbonato de cálcio. Este, por sua vez, fecha as fissuras e impede nova entrada de água (Koster et al., 2015). Sem água, as bactérias retornam à sua condição inicial de latência até que nova solicitação aconteça.

Para que a MICP por bactérias ureolíticas ocorra, é necessário que sejam disponibilizados nutrientes, que devem incluir fontes de cálcio e ureia, e água. A presença de água é imprescindível para o metabolismo bacteriano. Portanto, conforme apontam Luo et al. (2015) e Wang et al. (2014), a cura úmida é a mais indicada para compósitos cimentícios com bactérias. Algumas bactérias ureolíticas, como a Bacillus pasteurii e Bacillus subtilis são capazes de produzir ureia, outras necessitam que tal composto lhes seja fornecido por uma fonte externa (Vijay et al., 2017). Dentre os nutrientes mais utilizados em concretos auto-cicatrizantes com bactérias, estão o lactato de cálcio, acetato de cálcio, nitrato de cálcio e cloreto de cálcio (que servem como fonte de cálcio), além de ureia, extrato de levedura, água de maceração de milho e peptona. Em seu trabalho, Mondal e Ghosh (2018) 
introduziram bactérias do tipo Bacillus subtilis em concretos sem adicionar fontes de cálcio. Os autores constataram que o óxido de cálcio livre, presente no concreto, poderia ser utilizado pela bactéria, promovendo significativa precipitação de carbonato de cálcio tanto na superfície como no interior da matriz cimentícia.

\subsection{Influência do tipo e concentração de bactérias e nutrientes nos produtos formados}

$\mathrm{O}$ tipo e a concentração de bactérias e seus nutrientes têm grande influência na ocorrência da precipitação de carbonato de cálcio. Por exemplo, o tipo de bactéria afeta significativamente a morfologia dos cristais de carbonato formados ( $\mathrm{Li}$ et al. 2019). Dependendo do microorganismo escolhido, os cristais podem assumir a forma romboédrica mais densa ou mais espalhada, de pequenas esferas ou semi-esferas densas, no formato de manchas, hexaédricos, etc. Geralmente, o carbonato de cálcio precipitado assume a forma de cristais de calcita, mas também é possível que se apresente como cristais de vaterita e aragonita (Charpe et al., 2017, Kim et al. 2018, 2013, Joshi et al., 2018, Tittelboom et al., 2010, Amiri et al., 2018). A Tabela 1 apresenta os tipos de bactérias mais utilizados em pesquisas com materiais cimentícios realizadas nos últimos 10 anos.

Tabela 1. Tipos de bactérias usualmente utilizados em pesquisas com materiais cimentícios autocicatrizantes nos últimos 10 anos.

\begin{tabular}{|c|c|}
\hline Autor & Tipo de Bactéria \\
\hline Qian et al. (2009); Kim et al. (2013); Chahal et al. (2012); & \multirow{5}{*}{$\begin{array}{c}\text { Bacillus pasteurii / } \\
\text { Sporosarcina pasteurii }\end{array}$} \\
\hline Belie e Wang (2015); Zhang et al. (2015); Borges (2015); & \\
\hline Bashir et al. (2016); Bhaskar et al. (2017); Balam et al. (2017); & \\
\hline Choi et al. (2017); Jagannathan et al. (2017); Williams et al. (2017); & \\
\hline Amiri e Bundur (2018); Xu et al. (2018) & \\
\hline Tittelboom et al. (2010); Wang et al. (2012); Kim et al. (2013); & \multirow{4}{*}{ Bacillus sphaericus } \\
\hline Wang et al. (2014); Ersan et al. (2015); Bashir et al. (2016); & \\
\hline Seifan et al. (2016); Thiyagarajan et al. (2016); & \\
\hline Wang et al. (2017); Jagannathan et al. (2017) & \\
\hline Pei et al. (2013); Bashir et al. (2016); Khaliq e Ehsan (2016); & \multirow{3}{*}{ Bacillus subtilis } \\
\hline Huynh et al. (2017); Mondal et al. (2017); Rao et al. (2017); & \\
\hline Nain et al. (2019); Nguyen et al. (2019) & \\
\hline Achal et al. (2011a); Dhami et al. (2013); Andalib et al. (2016); & \multirow{2}{*}{ Bacillus megaterium } \\
\hline Vashisht et al. (2018); Nain et al. (2019) & \\
\hline Achal et al. (2011b); Achal e Pan (2014); Joshi et al. (2018) & Bacillus sp. \\
\hline
\end{tabular}

As bactérias do gênero Bacillus possuem formato de bastão, são formadoras de esporos e são comumente encontradas no solo. A Bacillus pasteurii, uma espécie deste gênero, é capaz de converter ureia em carbonato de amônio mais rapidamente que qualquer outra bactéria. Além disso, experimentos realizados com a Bacillus pasteurii mostram que a atividade de sua enzima urease é bem mais expressiva em ambientes com elevado $\mathrm{pH}$, favorecendo a precipitação de carbonato de cálcio nestas situações (Stocks-Fischer, 1999). Tais características aumentam a preferência por esta bactéria para a palicação em materiais comentícios auto-cicatrizantes.

A fonte de cálcio utilizada também influencia a morfologia dos cristais de carbonato de cálcio formados. Ambos Bhaskar et al. (2017) e Zhang et al. (2015) utilizaram a bactéria Sporosarcina pasteurii em seus experimentos. Porém, os primeiros utilizaram lactato de cálcio como fonte de cálcio enquanto os últimos fizeram testes com cloreto de cálcio, acetato de cálcio e nitrato de cálcio. Bhaskar et al. (2017) observaram a presença de cristais romboédricos dispersos, enquanto Zhang et al. (2015) obtiveram cristais hexaédricos, para o $\mathrm{CaCl}_{2}$ e $\mathrm{Ca}\left(\mathrm{NO}_{3}\right)_{2}$, e cristais aciculares, com pequenas quantidades de 
cristais esféricos e tipo alface, para o $\mathrm{Ca}\left(\mathrm{CH}_{3} \mathrm{COO}\right)_{2}$.

Quanto à concentração bacteriana, esta não interfere na morfologia dos cristais formados, mas na quantidade de precipitação e em sua taxa de formação (Mondal e Ghosh, 2018). Dentre as diversas concentrações de bactéria estudadas, muitos autores apontam um valor de cerca de $10^{5} \mathrm{cell} / \mathrm{mL}$ como a concentração ótima, capaz de otimizar a precipitação de $\mathrm{CaCO}_{3}$ e potencializar as efeitos do agente cicatrizante (Chahal et al., 2012, Rao et al.,2017, Jagannathan et al., 2017, Mondal e Ghosh, 2018). De acordo com Mondal e Ghosh. (2018), num primeiro momento, concentrações maiores precipitam maior quantidade de $\mathrm{CaCO}_{3}$ na superfície da fissura, porém, isto resulta na abstenção de água e oxigênio no interior da matriz, o que impede que a precipitação ocorra completamente.

\section{PROPRIEDADES DE COMPÓSITOS CIMENTÍCIOS COM BACTÉRIAS}

A introdução de bactérias em compósitos cimentícios altera algumas de suas propriedades. Uma vez precipitado, o carbonato de cálcio se deposita nas fissuras e nos poros do concreto, reduzindo sua porosidade e capacidade de absorção de água. Como consequência, a resistência mecânica aumenta. Estas propriedades são explorada nos subtópicos a seguir.

\subsection{Resistência à compressão}

Diversos autores investigam o efeito da adição de bactérias sobre a resistência mecânica de compósitos cimentícios. De maneira geral, o carbonato de cálcio formado densifica a microestrutura do compósito e aumenta sua resistência. Porém, situações como a introdução direta de nutrientes na pasta de cimento, podem ter efeito negativo na resistência. Wang et al. (2014) observaram que a adição de microcápsulas com bactérias teve um efeito negativo nas propriedades mecânicas de argamassas, dentre elas em sua resistência.

A Tabela 2 mostra os resultados de pesquisas, realizadas nos últimos 10 anos, acerca do efeito da adição de bactérias na resistência mecânica de materiais cimentícios. Segundo Nguyen et al. (2019), o ganho de resistência à compressão é altamente influenciado pelo tipo de bactéria e a concentração de células bacterianas utilizadas.

Tabela 2. Efeito da adição de diferentes tipos e concentrações de bactérias na resistência mecânica de materiais cimentícios.

\begin{tabular}{|c|c|c|c|c|}
\hline Autor & Bacteria & Material & $\begin{array}{c}\text { Concentração } \\
\text { (cell/ml) }\end{array}$ & $\begin{array}{l}\text { Acréscimo ou Decrécimo } \\
\text { de Resistência Mecânica } \\
\text { (28 dias) }\end{array}$ \\
\hline \multirow{2}{*}{ Nain et al. (2019) } & Bacillus subtilis & Concreto & $10^{8}$ & $14,46 \%$ \\
\hline & Bacillus megaterium & Concreto & $10^{8}$ & $22,58 \%$ \\
\hline \multirow{2}{*}{ Mondal et al. (2017) } & Bacillus cereus & Concreto & $10^{3}$ & $20 \%$ \\
\hline & Bacillus subtilis & Concreto & $10^{5}$ & $25 \%$ \\
\hline \multirow{3}{*}{$\begin{array}{l}\text { Mondal e Ghosh } \\
\text { (2018) }\end{array}$} & \multirow{3}{*}{ Bacillus subtilis } & \multirow{3}{*}{ Mortar } & $10^{3}$ & $15 \%$ \\
\hline & & & $10^{5}$ & $27 \%$ \\
\hline & & & $10^{7}$ & $19 \%$ \\
\hline Jonkers et al. (2010) & Bacillus cohnii & Pasta de cimento & $6 \times 10^{8}$ & $-10 \%$ \\
\hline Pei et al. (2013) & Bacillus subtilis & Argamassa & $10^{8}$ & $15 \%$ \\
\hline Wang et al. (2014) & Bacillus Sphaericus & Argamassa & $10^{9}$ & $-15 \%$ \\
\hline \multirow[b]{2}{*}{ Chahal et al. (2012) } & \multirow[b]{2}{*}{$\begin{array}{l}\text { Sporosarcina } \\
\text { pasteurii }\end{array}$} & Concreto & $10^{5}$ & $22 \%$ \\
\hline & & $\begin{array}{c}\text { Concreto com } 10 \% \\
\text { de cinza volante }\end{array}$ & $10^{5}$ & $20 \%$ \\
\hline
\end{tabular}




\subsection{Porosidade}

A deposição de $\mathrm{CaCO}_{3}$ nos poros do concreto reduz sua porosidade, o que aumenta a integridade da matriz cimentícia, melhora sua ligação e reduz a probabilidade de fissuras (Rao et al. 2017). A introdução de bactérias à pasta de cimento transforma os poros maiores em poros menores, com tamanho médio de 0,6-1,6 $\mu \mathrm{m}$, o que representa o tamanho típico de esporos bacterianos (Xu et al. 2018). Kunal et al. (2014), trataram pó de forno de cimento (Cement Kiln Dust - CKD) com bactérias do tipo Bacillus halodurans, adicionando-os a concretos com 10\% de CKD. Os autores verificaram que, a 91 dias, a porosidade havia sido reduzida em 12,35\%. De Muynck et al. (2007) misturaram bactérias do tipo Bacillus sphaericus em argamassas, e registraram uma redução de $45 \%$ na porosidade. Rao et al. (2017) verificaram, por meio de ensaio de pulso ultrasônico, uma redução de $70 \%$ na porosidade de amostras cimentícias com bactérias.

\subsection{Absorção de água}

A absorção de água por um material poroso está relacionada à interconectividade de seus poros. Em matrizes cimentícias com bactérias, o carbonato de cálcio precipitado reduz o tamanho dos poros, o que diminui sua conexão. Isto resulta numa menor absorção de água. $\mathrm{O}$ tipo e a concentração de bactérias influenciam na redução de absorção de água.

Kunal et al. (2014) estudaram o efeito da adição de bactérias Bacillus halodurans tratadas com pó de forno de cimento (CKD) na absorção de água de concretos com 10\% de CKD. Verificou-se que a absorção de água foi reduzida em 20\%. Wang et al. (2014) encapsularam esporos de Bacillus sphaericus em microcápsulas de melamina e as incorporaram em argamassas, adicionando seus nutrientes a parte. Uma redução de $30 \%$ na absorção de água foi observada nestas espécimes quando comparadas às espécimes de controle. Chahal et al. (2012) avaliaram a absorção de água em argamassas com diferentes porcentagens de cinza volante $(10 \%, 20 \%$ e $30 \%)$ e bactérias do tipo Bacillus pasteurii, com concentrações de $10^{3}, 10^{5}$ e $10^{7} \mathrm{cell} / \mathrm{mL}$. A espécime com $10 \%$ de cinza volante e concentração de células bacterianas igual a $10^{5} \mathrm{cell} / \mathrm{mL}$ apresentou a maior redução na adsorção de água, a qual foi de $77 \%$.

\section{EFICIÊNCIA DA TÉCNICA A CURTO E LONGO PRAZO}

A incorporação de agentes cicatrizantes (bactérias e seus nutrientes) na pasta de cimento é uma maneira promissora de selar fissuras abertas na primeiras idades do concreto (Wang et al., 2012). Tal ação aumenta a vida útil da edificação e reduz gastos com manutenção. Porém, o surgimento de fissuras em idades mais tardias ainda é um desafio para os agentes cicatrizantes bacterianos, dado que sua atividade metabólica se reduz ao longo do tempo (Luo et al., 2015). Isto ocorre devido à falta de nutrientes ou oxigênio para as bactérias, ao ambiente excessivamente alcalino do concreto, e ao fechamento dos poros da matriz cimentícia ao longo do tempo ( $\mathrm{Li}$ et al., 2019). Nestes casos, a reprodução das células bacterianas se torna inviável, levando à morte as colônias. Isso se reflete na diminuição da capacidade autocicatrizante do compósito ao longo do tempo.

Para aumentar a eficiência bacteriana na cicatrização de fissuras, diversos autores propõem o encapsulamento ou a imobilização dos microorganismos, por meio de materiais protetores. Tais técnicas aumentam as chances de sobrevivência das bactérias ao ambiente excessivamente alcalino do concreto (Jonkers et al., 2010). Na técnica de encapsulamento, as microcápsulas com bactérias e nutrientes são misturadas à matriz cimentícia durante a fabricação do concreto. Quando uma fissura é formada e atinge uma das cápsulas, ela se rompe, liberando as bactérias e seus nutrientes para o meio alcalino do material. Em contato com a água proveniente da fissura, as bactérias iniciam suas atividades metabólicas, culminando na precipitação de carbonato de cálcio, que sela a fissura.

Em seu trabalho, Wang et al. (2012) mostraram que bactérias da espécie Bacillus sphaericus imobilizadas em sílica gel e poliuretano mantiveram sua atividade ureolítica quase inalterada após 24 
semanas. Por outro lado, bactérias do gênero Bacillus, diretamente incorporadas a pastas de cimento por Jonkers et al. (2010) e Luo et al. (2015), tiveram seu número de células viáveis (vivas) significativamente reduzido ao longo do tempo, de modo que a 4 meses, esta número era mínimo. Esta redução pode ser vista no gráfico da Figura 1. Luo et al. (2015) reportaram, inclusive, que o efeito cicatrizante das bactérias era consideravelmente menor após 60 dias.

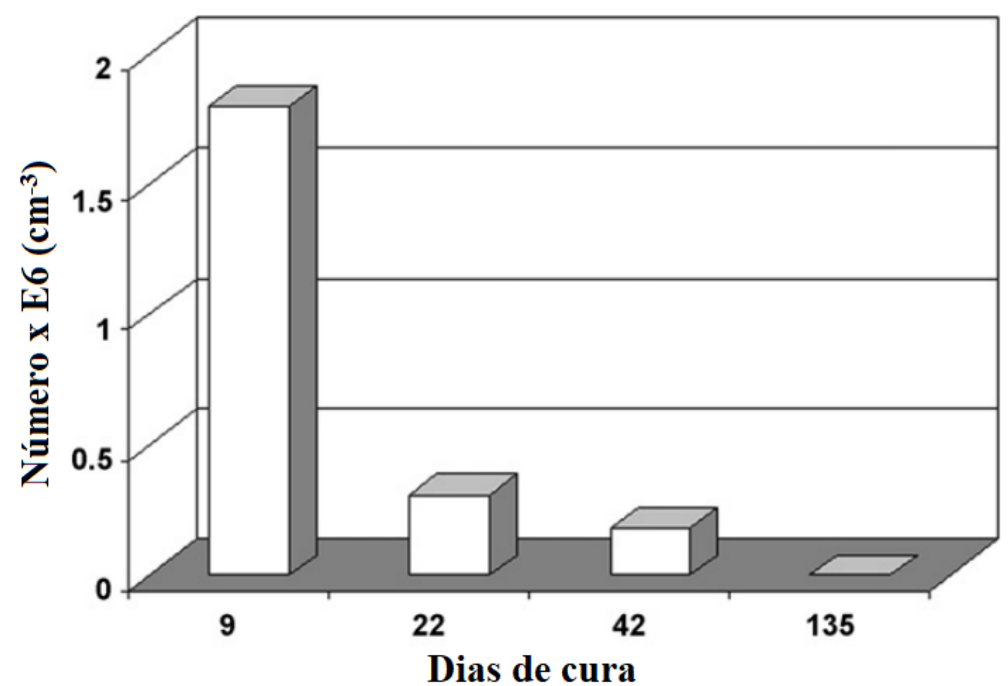

Figura 1. Estimativa do número mais provável de esporos bacterianos viáveis (Bacillus cohnii) incorporados em espécimes cimentícias envelhecidas (Adaptado de Jonkers et al., 2010).

O tipo de material de proteção utilizado também parece exercer influência sobre a eficiência da cicatrização. Wang et al. (2012) apontam que a imobilização do agente cicatrizante com sílica gel foi mais eficiente que a imobilização com poliuretano. Khaliq e Ehsan (2016) observaram que bactérias imobilizadas com nano-plaquetas de grafite foram mais eficazes no selamento de fissuras abertas a $3 \mathrm{e}$ 7 dias, enquanto bactérias imobilizadas por agregados leves apresentaram melhor desempenho a $14 \mathrm{e}$ 28 dias.

De acordo com Ersan et al. (2015) e Van Tittelboom et al. (2010), bactérias desprotegidas não sobrevivem por longos períodos dentro da pasta de cimento, nem são capazes de selar fissuras por completo. Por isso, a utilização de materiais de proteção se mostra como um caminho viável para a obtenção de maior eficiência na técnica de auto-cicatrização, especialmente a longo prazo. Todavia, é importante garantir que a presença do material de proteção não interfira negativamente nas propriedades mecânicas do compósito, como ocorreu no trabalho de Wang et al. (2014). Neste sentido, pesquisas em torno de materiais de proteção funcionais e economicamente viáveis para encapsulamento ou imobilização de bactérias devem ser fomentadas.

Outras soluções para a questão da eficiência a longo prazo também devem ser exploradas. Uma delas, proposta por Borges (2015), trata da introdução direta da enzima urease nos materiais cimentícios, tendo sido ela previamente extraída das bactérias ureolíticas. De fato, a enzima urease é a real responsável pela indução da precipitação de carbonato de cálcio, cabendo à bactéria a função de produzi-la. Os resultados obtidos pelo autor são promissores, revelando que o uso da enzima de maneira isolada pode ser tão eficaz quanto a aplicação das bactérias, ou até mais, com a vantagem de que, no caso da enzima isolada, o efeito cicatrizante a longo prazo tende a ser bem maior. A Tabela 3 mostra os principais resultados obtidos por Borges (2015).

Outros autores, como Williams et al. (2017) e Pei et al. (2013), se empenham em entender o papel que células inativas, isto é, células mortas têm na matriz cimentícia. Os autores observaram que estas células funcionam como pontos de nucleação heterogênea para a precipitação de carbonato de cálcio, uma vez que sua superfície permanece negativamente carregada, mesmo após sua morte. Foi verificado um 
aumento na quantidade de $\mathrm{CaCO}_{3}$ em pastas de cimento com células inativas de Sporosarcina pasteurii, o que, conforme Williams et al. (2017), foi $62 \%$ maior que em pastas de cimento puras.

Tabela 3. Parâmetros de argamassas modificadas por bactérias e pela enzima urease isolada, comparados com espécimes de controle curadas em água (Adaptado de Borges, 2015)

\begin{tabular}{|c|c|c|c|c|}
\hline & $\begin{array}{c}\text { Massa específica } \\
\left(\mathbf{k g} / \mathbf{m}^{3}\right)\end{array}$ & $\begin{array}{c}\text { Velocidade de } \\
\text { pulso ultrsônico } \\
(\mathrm{m} / \mathrm{s})\end{array}$ & $\begin{array}{c}\text { Módulo de } \\
\text { Elasticidade (Gpa) }\end{array}$ & $\begin{array}{l}\text { Absorção de água por } \\
\text { capilaridade }(\%)\end{array}$ \\
\hline Bactéria & 1869,8 & 2781,7 & 11,9 & 8,6 \\
\hline Enzima & 1913,5 & 2839 & 13,2 & 8,6 \\
\hline Água & 1862,5 & 2626,5 & 10,5 & 10,0 \\
\hline
\end{tabular}

\section{EFICIÊNCIA NA CICATRIZAÇÃO DE FISSURAS}

O processo de autocicatrização de fissuras no concreto com bactérias ocorre pela precipitação de cristais de calcita, seguida de sua deposição em ambas as faces da fissura, indo em direção ao meio (Qian et al., 2009). A largura máxima reparável de fissuras não depende, porém, do tipo de bactéria empregado, mas do método de aplicação destas no compósito cimentício (Li et al., 2019).

Luo et al. (2015) incorporaram bactérias álcali-resistentes e seus nutrientes diretamente à pastas de cimento e água. Após 20 dias, fissuras de $0,3 \mathrm{~mm}$ haviam sido quase totalmente seladas. Nguyen et al. (2019) adicionaram bactérias do tipo Bacillus subtilis e seus nutrientes diretamente à água de mistura de concretos. A 44 dias, fissuras de 0,4mm haviam sido completamente seladas. Wiktor et al. (2011) imobilizaram bactérias da espécie Bacillus alkalinitrilicus e lactato de cálcio em agregados de argila expandida, incorporando-os ao concreto. Após 100 dias, fissuras de 0,46mm haviam sido fechadas. Zhang et al. (2017) imobilizaram bactérias do tipo Bacillus cohnii em perlita expandida, incorporandoas a amostras de concreto. A 28 dias, fissuras de $0,79 \mathrm{~mm}$ haviam sido completamente seladas. Wang et al. (2014) encapsularam bactérias Bacillus sphaericus, nutrientes e nitrato de cálcio em microcápsulas orgânicas, introduzindo-as em argamassas. Verificou-se que fissuras de até $0,97 \mathrm{~mm}$ haviam seladas. Conforme pontuam Vijay et al. (2017), bactérias encapsuladas têm mostrado os melhores resultados quanto à capacidade de cicatrização de fissuras.

A introdução de nutrientes na matriz cimentícia pode comprometer seu tempo de pega e resistência mecânica. Deste modo, a limitação na quantidade de nutrientes fornecida culmina na redução da capacidade cicatrizante das bactérias, a qual se restringe a fissuras menores que $1 \mathrm{~mm}$ de diâmetro (Charpe et al., 2017; Jonkers et al., 2010). A imobilização dos nutrientes em materiais de proteção é apontada como uma solução para esta questão (Xu et al., 2018). Verifica-se, desta forma, que tanto a eficiência a longo prazo, quanto a capacidade cicatrizante são melhoradas pelo uso de materiais protetores.

\section{CONCLUSÕES}

A precipitação de carbonato de cálcio, induzida por bactérias incorporadas a materiais cimentícios, se mostra como uma técnica promissora para a cicatrização de fissuras formadas nas primeiras idades do compósito. A eficiência da técnica após longos períodos, porém, depende do encapsulamento ou imobilização das bactérias e seus nutrientes em materiais de proteção. Nestes sentido, são necessários estudos mais aprofundados em torno destes materiais, a fim de que sejam funcionais e economicamente viáveis, e não afetem negativamente propriedades mecânicas, como a resistência à compressão. Estudos alternativos, como a aplicação da enzima urease sem a bactéria também devem ser fomentados. 


\section{REFERÊNCIAS}

ABNT - Associação Brasileira de Normas Técnicas. (2014). NBR 6118; Projeto de estruturas de concrete - Procedimento. Rio de Janeiro.

Achal, V., Mukherjee, A., Reddy, M. S. (2011a), "Microbial concrete: Way to enhance the durability of building structures", Journal of Materials in Civil Engineering, V.23, p.730-734. https://doi.org/10.1061/(ASCE)MT.1943-5533.0000159

Achal, V., Pan, X., Ozyurt, N. (2011b) "Improved strength and durability of fly ash-amended concrete by microbial calcite precipitation" Ecological Engineering, V.37, p.554-559.

Amiri, A., Bundur, Z. B. (2018) "Use of corn-steep liquor as an alternative carbono source for biomineralization in cement-based materials and its impacto $n$ performance" Construction and Building Materials, V.165, p.655-662. https://doi.org/10.1016/j.conbuildmat.2018.01.070

Balam, N. H., Mostofinejad, D., Eftekhar, M. (2016) "Effects of bacterial remediation on compressive strength, water absorption, and chloride permeability of lightweight aggregate concrete" Construction and Building Materials, V.145, p.107-116.

https://doi.org/10.1016/j.conbuildmat.2017.04.003

Bashir, J., Kathwari, I., Tiwary, A., et al. (2016) Bio concrete-the self-healinf concrete" Indian Journal of Science and Technology, V.9, p.1-5.

Bhaskar, S., Anwar Hossain, K. M., Lachemi, M., et al. (2017) "Effect of self-healing on strength and durability of zeolite-immobilized bacterial cementitious mortar composites" Cement and Concrete Composites, V.82, p.23-33. https://doi.org/10.1016/j.cemconcomp.2017.05.013

De Belie, N. Wang, J. Y. (2015) "Bacteria-based repair and self-healing of concrete" Journal of Sustainable Cement Based-Materials, V.5, p.35-56.

https://doi.org/10.1080/21650373.2015.1077754

Borges, H. M. R. R. (2015) "Bio-cimentação como técnica de reparação de argamassas cimentícias", Dissertação de Mestrado, Universidade de Lisboa, p.7.

Chahal, N., Siddique, R., Rajor, A. (2012) "Influence of bacteria on the compressive strength, water absorption and rapid chloride permeability of fly ash concrete" Construction and Building Materials, V.28, p.645-651. https://doi.org/10.1016/j.conbuildmat.2011.07.042

Charpe, A. U., Latkar, M. V., Chakrabarti, T. (2017), "Microbially assisted cementation - a biotecnological approach to improve mechanical properties of cement", Construction and Building Materials, V.135, p.472-476. https://doi.org/10.1016/j.conbuildmat.2017.01.017

Choi, S., Wang, K., Wen, Z., et al. (2017) "Mortar crack repair using microbial induced calcite precipitation method" Cement and Concrete Composites, V.83, p.209-221. https://doi.org/10.1016/j.cemconcomp.2017.07.013

Ersan, Y. C., Silva, F. B. D., Boon, N., et al. (2015) "Screening of bacteria and concrete compatible protection materials" Construction and Building Materials, V.88, p.196-203.

https://doi.org/10.1016/j.conbuildmat.2015.04.027

Huynh, N. N. T., Phuong, N. M., Toan, N. P. A., Son, N. K. (2017) “Bacillus subtilis HU58 immobilized in micropores of diatomite for using in self-healing concrete" Procedia Engineering, V.171, p.598-605. https://doi.org/10.1016/j.proeng.2017.01.385

Jonkers, H. M., (2007) "Self-healing concrete: a biological approach". In Self Healing Materials. An Alternative Approach to 20 Centuries of Materials Science; van der Zwaag, S., Ed.; Springer: Dordrecht, V.100, p.195-204.

Jonkers, H. M., Thijssen, A., Muyzer, G. Copuroglu, O., Schlangen, E. (2010) "Application of bacteria as self-healing agente fot thr development of sustainable concrete”, Ecological Engineering, V.36, p.230-235. https://doi.org/10.1016/j.ecoleng.2008.12.036

Khaliq, W., Ehsan, M. B. (2016) "Crack healing in concrete using various bio influenced self-healing techniques" Construction and Building Materials, V.102, p.349-357. 
https://doi.org/10.1016/j.conbuildmat.2015.11.006

Kim, H. K., Park, S. J., Han, J. L., et al. (2013) "Microbially mediated calcium carbonate precipitation on normal and lightweight concrete" Construction and Building Materials, V.38, p.1073-1082. https://doi.org/10.1016/j.conbuildmat.2012.07.040

De Koster, S. A. L., Mors, R. M., Nugteren, H. W., Jonkers, H. M., Meesters, G. M. H., van Ommen, J. R. (2015) "Geopolymer coating of bacteria-containing granules for use in self-healing concrete", Procedia Engineering, V.102, p.475-484. https://doi.org/10.1016/j.proeng.2015.01.193

Kunal, Siddique, R., Rajor, A. (2014) "Influence of bacteril treated cement kiln dust on the properties of concrete" Construction and Building Materials, V.52, p.42-51.

https://doi.org/10.1016/j.conbuildmat.2013.11.034

Jagannathan, P., Narayanana, K. S. S., Arunachalamb, K. D. et al. (2017) "Studies on the mechanical properties of bacterial concrete with two bacterial species" Materials Today: Proceedings, V.5, p.88758879. https://doi.org/10.1016/j.matpr.2017.12.320

Li, L., Zheng, Q., Li, Z., Ashour, A., Han, B. (2019) “Bacterial technology-enabled cementitious composites: A review" Composite Structures, V.225.

https://doi.org/10.1016/j.compstruct.2019.111170

Luo, M., Qian, C., Li, R. (2015) "Factors affecting crack repairing capacity of bacteria-based selfhealing concrete", Construction and Building Materials, V.87, p.1-7.

https://doi.org/10.1016/j.conbuildmat.2015.03.117

Mondal, S., Das, P., Chakraborty, A. K. (2017) “Application of bacteria in concrete” Materials Today, V.4, p.9833-9836. https://doi.org/10.1016/j.matpr.2017.06.276

Mondal, S., Ghosh, A. D. (2018) "Investigation into the optimal bacterial concentration for compressive strength enhancement of microbial concrete" Construction and Building Materials, V.183, p.202-214.

Mondal, S., Ghosh, A. (2019) "Review on microbial induced calcite precipitation mechanisms leading to bacterial selection for microbial concrete", Construction and Building Materials, V.225, p.67-75. https://doi.org/10.1016/j.conbuildmat.2019.07.122

Nain, N., Surabhi, R., Yathish, N. V., Krishnamurthy, V., Deepa, T., Tharannum, S. (2019) "Enhancement in strength parameters of concrete by application of Bacillus bacteria" Construction and Building Materials, V.202, p.904-908.

https://doi.org/10.1016/j.conbuildmat.2019.01.059

Nguyen, T. H., Ghorbel, E., Fares, H., Cousture, A. (2019) "Bacterial self-healing of concrete and durability assessment", Cement and Concrete Composites, V.104.

https://doi.org/10.1016/j.cemconcomp.2019.103340

Pei, R., Liu, J., Wang, S., Yang, M. (2013) "Use of bacterial cell walls to improve the mechanical performance of concrete" Cement and Concrete Composite, V.39, p.122-130. https://doi.org/10.1016/j.cemconcomp.2013.03.024

Qian, S., Zhou, J., De Rooij, M. R., Schlangen, E., Ye, G., Van Breugel, K. (2009) "Self-healing behavior of strain hardening cementitious composites incorporating local waste materials", Cement and Concrete Composites, V.3, p.613-621. doi:10.1016/j.cemconcomp.2009.03.003

Ramachandran, S. K., Ramashandran, V., Bang, S. S. (2001) "Remediation of concrete using microorganisms" ACI Materials Journal, V.98, p.3-9.

Rao, M. V. S, Reddy, V. S., Sasikala, C. (2017) "Performance of microbial concrete developed using bacteria subtilus JC3" Journal of the Institute of Engineering (India): Series A, V.98, p.501-510. https://doi.org/10.1007/s40030-017-0227-X

Seifan, M., Samani, A. K., Berenjian, A. (2016) "Induced calcium carbonate precipitation using Bacillus species" Applied Microbiology and Biotechnology, V.100, p.9895-9906.

https://doi.org/10.1007/s00253-016-7701-7

Siddique, R., Chahal, N. K. (2011) "Effect of ureolytic bacteria on concrete properties", Construction and Building Materials, V.25, p.3791-3801. 
https://doi.org/10.1016/j.conbuildmat.2011.04.010

Siddique, R., Kunal, V. N., Kadri, E., et al. (2016) "Influence of bacteria on compressive strength and permeation properties of concrete made with cement caghouse filter dust", Construction and Building Materials, V.106, P.461-469. https://doi.org/10.1016/j.conbuildmat.2015.12.112

Thiyagarajan, H., Maheswaran, S., Mapa, M., et al. (2016) "Investigation of bacterial activity on compressive strength of cement mortar in diferente curing media" Journal of Advanced Concrete Technology, V.14, p.125-133. https://doi.org/10.3151/jact.14.125

Van Tittelboom, K., De Belie, N., De Muynck, W., et al. (2010) "Use of bacteria to repair cracks in concrete", Cement and Concrete Research, V.40, p.157-166.

http://dx.doi.org/10.1016/j.cemconres.2009.08.025

Wang, J., Van Tittelboom, K., De Belie, N., Verstraete, W. (2012) “Use of silica gel or polyurethane immobilized bacteria for self-healing concrete", Construction and Building Materials, V.26, p.532-540. https://doi.org/10.1016/j.conbuildmat.2011.06.054

Wang, J. Y., Soens, H., Verstraete, W., De Belie, N. (2014) "Self-healing concrete by use of microencapsulated bacterial spores", Cement and Concrete Research, V.56, p.139-152. https://doi.org/10.1016/j.cemconres.2013.11.009

Wang, J. Y., Jonkers, H. M., Boon, N., Belie, D. B. (2017) "Bacillus sphaericus LMG 22257 is physiologically suitable for self-healing concrete" Applied Microbiology e Biotechnology, V.101, p.5101-5114. https://doi.org/10.1007/s00253-017-8260-2

Wiktor, V., Jonkers, H. M. (2011) "Quantification of crack-healing in novel bacteria-based self-healing concrete", Cement and Concrete Composites, V.33, p.763-770.

https://doi.org/10.1016/j.cemconcomp.2011.03.012

Williams, S. L., Kirisits, M. J., Ferron, R. D. (2017) “Influence of concrete-related environmental stressors on biomineralizing bacteria used in self-healing concrete" Construction and Building Materials, V.139, p.-611-618. https://doi.org/10.1016/j.conbuildmat.2016.09.155

$\mathrm{Xu}$, J., Wang, X., Wang, B. (2018) "Biochemical process of ureolysis-based microbial $\mathrm{CaCO}_{3}$ precipitation and its application in self-healing concrete", Applied Microbiology and Biotechnology, V.102, p.3121-3132. https://doi.org/10.1007/s00253-018-8779-X

Zhang, Y., Guo, H. X., Cheng, X. H. (2015) "Role of calcium sources in the strength and microstructure of microbial mortar" Construction and Building Materials, V.77, p.160-167. https://doi.org/10.1016/j.conbuildmat.2014.12.040 